\title{
ANALISIS PENGGUNAAN MODAL KERJA DALAM MENINGKATKAN LABA PADA INDUSTRI SEJAHTERA MANDIRI DI KECAMATAN MALANGKE BARAT KABUPATEN LUWU UTARA
}

\author{
Goso' \\ Indriani ${ }^{2}$
}

No. HP $081343798848^{1}$

\section{ABSTRAK}

Penelitian ini bertujuan untuk mengetahui dan menganilisis penggunaan modal kerja dalam meningkatkan laba pada industri sejahtera mandiri. Metode analisis data yang digunakan adalah Gross Profit Margin yang digunakan untuk mengukur kemampuan perusahaan dalam mendapatkan laba bruto per rupiah penjualan, Operating Profit Margin yang digunakan untuk mengukur kemampuan perusahaan dalam menghasilkan laba operasi sebelum bunga dan pajak yang dihasilkan oleh setiap rupiah penjualan dan Net Profit Margin yang digunakan untuk menunjukkan kemampuan perusahaan dalam menghasilkan keuntungan bersih. Berdasarkan analisis data yang digunakan maka dapat diketahui bahwa penggunaan modal kerja yang digunakan dalam menghasilkan laba baik berupa laba kotor maupun laba sebelum bunga dan pajak serta laba bersih selalu mengalami peningkatan setiap tahunnya.

Kata kunci: Industri Sejahtera Mandiri, Peningkatan laba, Penggunaan Modal Kerja.

\section{PENDAHULUAN}

Situasi dunia bisnis sekarang ini menuntut para usaha-usahawan yang ada untuk senantiasa meningkatkan efisiensinya. Hal ini dapat dimaksudkan agar perusahaan dapat tetap "survive" dan bersaing dengan usahaan-usaha lainnya dengan tujuan adalah untuk memperoleh profit atau keuntungan yang maksimal dan continue. Didasari dengan hal tersebut maka yang harus diperhatikan adalah penggunaan modal kerja, dimana penggunaan modal kerja merupakan masalah pokok dan topik penting yang sering kali dihadapi oleh perusahaan, karena hampir semua perhatian untuk mengelola modal kerja dan aktiva lancar yang merupakan bagian yang cukup besar dari aktiva. Besar kecilnya modal kerja dapat ditambah atau dikurangi sesuai kebutuhan perusahaan. Pengelolaan modal kerja merupakan hal yang sangat penting dalam perusahaan, karena meliputi pengambilan keputusan mengenai jumlah dan komposisi aktiva lancar. Perusahaan yang tidak memiliki pengolahaan modal kerja yang baik akan menimbulkan inefisiensi atau pemborosan dalam operasi perusahaan dan dapat pula perusahaan overlikuid sehingga menimbulkan dana mengaggur yang akan mengakibatkan inefisiensi perusahaan, dan membuang kesempatan memperoleh laba. Sementara Laba hanya bisa diperoleh dengan adanya kinerja yang baik dari perusahaan itu sendiri. 


\section{METODE PENELITIAN}

Penulis melakukan penelitian pada Industri Sejahtera Mandiri yang berlokasi di Jln. To Semmaele Dusun Amassangan Desa Pao Kecematan Malangke Barat Kabupaten Luwu Utara. Berdasarkan hipotesis yang telah dikemukakkan, maka untuk mendapatkan informasi sebagai bahan analisis diperlukan data-data yang ralevan dan dapat menunjung kebenaran hipotesis tersebut yaitu data primer dan data sekunder.

\section{Metode Analisis Data}

Dalam menganalisis data yang telah ada, penulis menggunakan metode analisis Rasio Profitabilitas atau Rasio Keuntungan untuk mengukur seberapa besar kemampuan perusahaan memperoleh laba dalam hubungannya dengan penjualan, aktiva maupun laba dan modal sendiri. Adapun metode analisis yang digunakan yaitu :

1. Gross Profit Margin, digunakan untuk mengukur kemampuan perusahaan dalam mendapatkan laba bruto per rupiah penjualan. Dapat dihitung dengan rumus sebagai berikut :

Gross Profit Margin $=\frac{\text { Penjualan Bersih }- \text { HPP }}{\text { Penjualan Bersih }}$ $\times 100 \%$

2. Operating Profit Margin, digunakan untuk mengukur kemampuan perusahaan dalam menghasilkan laba operasi sebelum bunga dan pajak yang dihasilkan oleh setiap rupiah penjualan. Dapat dihitung dengan rumus sebagai berikut :

$$
\mathrm{OPM}=\frac{\mathrm{EBIT}}{\text { Penjualan Bersih }} \times 100 \%
$$

3. Net Profit Margin (NPM), digunakan untuk menunjukkan kemampuan perusahaan dalam menghasilkan keuntungan bersih. Dapat dihitung dengan rumus sebagai berikut :

$$
\mathrm{NPM}=\frac{\mathrm{EAT}}{\text { Penjualan }} \times 100 \%
$$

\section{HASIL PENELITIAN DAN PEMBAHASAN}

Berdasarkan hasil penelitian yang dilakukan maka dapat diketahui perkiraan jumlah modal kerja yang digunakan pada Industri Sejahtera Mandiri setiap tahunnya dengan rata-rata senilai Rp.78.856.000 untuk memenuhi kebutuhan persediaan keripik rumput laut dengan rata-rata sebanyak 7.752 kemasan.

Besar kecilnya modala kerja yang digunakan sangat ditentukan oleh permintaan pelanggan. Permintaan produk berpengaruh langsung terhadap jumlah produksi. Modal kerja yang digunakan berasal dari modal sendiri dan modal pinjaman dari PNPM.

Berikut adalah tabel Penjualan, tabel Penentuan Harga Pokok Produksi (HPP) dan tabel Laporan Laba Rugi pada Industri Sejahtera Mandiri:

Tabel 1: Penjualan Pada Industri Sejahtera Mandiri dari tahun 2011- 2014

\begin{tabular}{|c|c|c|c|c|}
\hline No & Tahun & Kemasan & Harga & Total \\
\hline 1 & 2011 & 2.400 & $\begin{array}{c}\text { RP. } \\
10.000\end{array}$ & $\begin{array}{c}\text { Rp. } \\
24.000 .000\end{array}$ \\
\hline 2 & 2012 & 6.857 & $\begin{array}{c}\text { RP. } \\
10.000\end{array}$ & $\begin{array}{c}\text { Rp. } \\
68.570 .000\end{array}$ \\
\hline 3 & 2013 & 14.000 & $\begin{array}{c}\text { RP. } \\
10.000\end{array}$ & $\begin{array}{c}\text { Rp. } \\
144.000 .000\end{array}$ \\
\hline
\end{tabular}


Berdasakan data di atas maka dapat diketahui jumlah penjualan dari tahun 2011 sampai 2014 adalah sebagai berikut: pada tahun 2011 senilai $R p$. 24.000.000, pada tahun 2012 senilai Rp.68.570.000 dan pada tahun 2013 senilai Rp. 144.000 .000 .

Tabel 2

Penentuan Harga Pokok Produksi pada Industri Sejahtera Mandiri periode 2011-2013

\begin{tabular}{|c|c|c|c|}
\hline \multirow{2}{*}{ Rincian } & \multicolumn{3}{|c|}{ 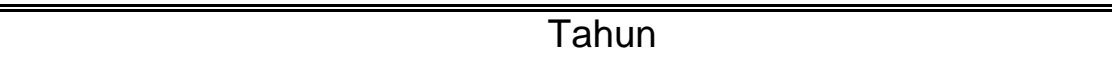 } \\
\hline & 2011 & 2012 & 2013 \\
\hline Biaya Bahan Baku & Rp. 11.745 .000 & Rp. 34.275.000 & Rp. 69.423 .000 \\
\hline Biaya Bahan Pembantu & Rp. $\quad 360.000$ & Rp. 1.378 .000 & Rp. 3.600 .000 \\
\hline Biaya tenaga Kerja & & & \\
\hline Langsung & Rp. 2.520 .000 & Rp. $\quad 6.720 .000$ & Rp. 12.600 .000 \\
\hline Biaya Overhead Pabrik & 864.000 & Rp. 1.200 .000 & Rp. 2.304 .000 \\
\hline Harga Pokok Produksi & Rp. 15.489.000 & Rp.43.573.000 & Rp. 87.927.000 \\
\hline
\end{tabular}

Sumber: Data Primer

Berdasrkan data di atas maka dapat diketahui harga pokok produksi pada Industri Sejahtera Mandiri dari tahun 2011 sampai tahun 2013 dimana pada tahun 2011 sebesar Rp.15.489.000, tahun 2012 sebesar Rp.43.573.000 dan pada tahun 2013 sebesar Rp.87.927.000. Dari hasil tersebut maka dapat kita ketahui bahwa harga pokok produksi setiap tahunnya mengalami kenaikan disebabkan oleh bertambahnya jumlah biaya-biaya yang dikeluarkan yang disesuaikan dengan kebutuhan industri tersebut. 
Tabel 3

Laporan Laba Rugi Pada Industri Sejahtera Mandiri Periode 2011-2013

\begin{tabular}{|c|c|c|c|}
\hline \multirow{2}{*}{ Rincian } & \multicolumn{3}{|c|}{ Tahun } \\
\hline & 2011 & 2012 & 2013 \\
\hline Penjualan & Rp. 24.000.000 & Rp. 68.570.000 & Rp. 144.000 .000 \\
\hline Biaya Produksi & & & \\
\hline Biaya Bahan Baku & Rp. 11.745 .000 & Rp. 34.275 .000 & Rp. 69.423 .000 \\
\hline Biaya Bahan Pembantu & Rp. $\quad 360.000$ & Rp. 1.378 .000 & Rp. $\quad 3.600 .000$ \\
\hline Biaya Tenaga Kerja & & & \\
\hline Langsung & Rp. 2.520 .000 & Rp. 6.720 .000 & Rp. 12.600 .000 \\
\hline Biaya Overhead Pabrik & Rp. $\quad 864.000$ & Rp. $\quad 1.200 .000$ & Rp. $\quad 2.304 .000$ \\
\hline Harga Pokok Penjualan & & & \\
\hline (HHP) & Rp. 15.489 .000 & Rp. 43.573 .000 & Rp. 87.927 .000 \\
\hline Laba kotor & Rp. 8.511 .000 & Rp. 24.997.000 & Rp. $\quad 56.073 .000$ \\
\hline Biaya Pemasaran & Rp. $\quad 300.000$ & Rp. $\quad 600.000$ & Rp. $\quad 1.320 .000$ \\
\hline EBIT & Rp. 8.211 .000 & Rp. 24.397.000 & Rp. 54.753 .000 \\
\hline Pajak 1\% x EBIT & Rp. $\quad 82.110$ & Rp. $\quad 243.970$ & Rp. $\quad 547.530$ \\
\hline Bunga $1 \% \times$ Rp. & & & \\
\hline 20.000.000/bulan x 12 bulan & Rp. 2.400 .000 & Rp. 2.400 .000 & Rp. $\quad 2.400 .000$ \\
\hline Laba bersih (EAT) & Rp. 5.728 .890 & Rp. 21.753 .030 & Rp. 51.805 .470 \\
\hline
\end{tabular}

\section{Pembahasan Hasil Penelitian}

Berdasarkan data di atas, maka analisis data yang digunakan untuk menganalisis penggunaan modal kerja dalam meningkatkan laba yaitu Gross Profit Margin, Operating Profit Margin, dan Net Profit Margin setiap tahunnya dapat dihitung sebagai berikut: a. Gross Profit Margin

Gross Profit Margin yang digunakan untuk mengukur kemampuan perusahaan dalam mendapatkan laba bruto per rupiah penjualan sebagai berikut :

1. Gross Prifit Margin tahun 2011

$$
\begin{aligned}
\text { Gross Profit Margin } & =(\text { Penjualan Bersih-HPP }) /(\text { Penjualan Bersih }) \times 100 \% \\
& =(\text { Rp. } 24.000 .000-\text { Rp. 15.489.000) } /(\text { Rp. } 24.000 .000) \times 100 \% \\
& =(\text { Rp. } 8.511 .000) /(\text { Rp. } 24.000 .000) \times 100 \% \\
& =35,46 \%
\end{aligned}
$$

Artinya bahwa setiap penjualan bersih 100 persen mampu memberikan tambahan laba kotor sebesar 35,46 persen. 
2. Gross Prifit Margin tahun 2012

$$
\begin{aligned}
\text { Gross Profit Margin } & =(\text { Penjualan Bersih }- \text { HPP }) /(\text { Penjualan Bersih }) \times 100 \% \\
& =(\text { Rp.68.570.000 }- \text { Rp.43.573.000) } /(\text { Rp. } 68.570 .000) \times 100 \% \\
& =(\text { Rp. } 24.997 .000) /(\text { Rp.68.570.000 }) \times 100 \% \\
& =36,45 \%
\end{aligned}
$$

Artinya bahwa setiap penjualan bersih 100 persen mampu memberikan tambahan laba kotor sebesar 36.45 persen.

3. Gross Prifit Margin tahun 2013

$$
\begin{aligned}
\text { Gross Profit Margin } & =(\text { Penjualan Bersih }- \text { HPP }) /(\text { Penjualan Bersih }) \times 100 \% \\
& =(\text { Rp. } 144.000 .000-\text { Rp.87.927.000) } /(\text { Rp. } 144.000 .000) \times 100 \% \\
& =(\text { Rp. } 56.073 .000) /(\text { Rp. } 144.000 .000) \times 100 \% \\
& =38,94 \%
\end{aligned}
$$

Artinya bahwa setiap penjualan bersih 100 persen mampu memberikan tambahan laba kotor sebesar 38.94 persen.

\section{Semakin besar persentase} laba kotor yang diperoleh pada Industri Sejahtera Mandiri maka semakin efisien penggunaan biaya operasional pada Industri tersebut. b. Operating Profit Margin

Operating Profit Margin yang digunakan untuk mengukur kemampuan perusahaan dalam menghasilkan laba operasi sebelum bunga dan pajak yang dihasilkan oleh setiap rupiah penjualan sebagai berikut :

1. Operating Profit Margin 2011

$$
\begin{aligned}
\text { Operating Profit Margin } & =\text { EBIT } /(\text { Penjualan bersih }) \times 100 \% \\
& =(\text { Rp. } 24.397 .000) /(\text { Rp. } 68.570 .000) \times 100 \% \\
& =35,58 \%
\end{aligned}
$$

Artinya setiap penjualan bersih 100 persen mampu memberikan tambahan laba operasi sebelum bunga dan pajak sebesar 35,58 persen.

\section{Operating Profit Margin 2012}

$$
\begin{aligned}
\text { Operating Profit Margin } & =\text { EBIT/(Penjualan bersih }) \times 100 \% \\
& =(\text { Rp. } 8.211 .000) /(\text { Rp. } 24.000 .000) \times 100 \% \\
& =34,21 \%
\end{aligned}
$$

Artinya setiap penjualan bersih 100 persen mampu memberikan tambahan laba operasi sebelum bunga dan pajak sebesar 34,21 persen. 
3. Operating Profit Margin 2013

$$
\begin{aligned}
\text { Operating Profit Margin } & =\text { EBIT/(Penjualan bersih }) \times 100 \% \\
& =(\text { Rp. } 54.753 .000) /(\text { Rp. } 144.000 .000) \times 100 \% \\
& =38,02 \%
\end{aligned}
$$

Artinya setiap penjualan bersih 100 persen mampu memberikan tambahan laba operasi sebelum bunga dan pajak sebesar 38,02 persen.

Semakin besar

persentase laba operasi

sebelum bunga dan pajak yang

diperoleh pada Industri

Sejahtera Mandiri maka

semakin efisien penggunaan

biaya operasional pada Industri

tersebut. c. Net Profit Margin (NPM), digunakan untuk menunjukkan kemampuan perusahaan dalam menghasilkan keuntungan bersih dihitung sebagai berikut:

1. Net Profit Margin 2011

Net Profit Margin = EAT/Penjualan $\times 100 \%$

$$
\begin{aligned}
& =(\text { Rp. 5.728.890) } /(\text { Rp. } 24.000 .000) \times 100 \% \\
& =23,87 \%
\end{aligned}
$$

Artinya setiap penjualan 100 persen mampu memberikan tambahan laba bersih (laba sesudah bunga dan pajak) sebesar 23,87 persen.

$$
\begin{aligned}
\text { Net Profit Margin } & =\text { EAT/Penjualan } \times 100 \% \\
& =(\text { Rp. } 21.753 .030) /(\text { Rp. } 68.570 .000) \times 100 \% \\
& =31,72 \%
\end{aligned}
$$

Artinya setiap penjualan 100 persen mampu memberikantambahan laba bersih (laba sesudah bunga dan pajak) sebesar 31,72 persen.

\section{Net Profit Margin 2012}

$$
\begin{aligned}
\text { Net Profit Margin } & =\text { EAT/Penjualan } \times 100 \% \\
& =(\text { Rp. } 51.805 .470) /(\text { Rp. } 144.000 .000) \times 100 \% \\
& =35,98 \%
\end{aligned}
$$

Artinya setiap penjualan 100 persen mampu memberikan tambahan laba bersih (laba sesudah bunga dan pajak) sebesar 35,98 persen. 
3. Net Profit Margin 2013

Semakin besar persentase laba bersih yang diperoleh pada Industri Sejahtera Mandiri maka semakin efisien penggunaan biaya operasional pada Industri tersebut.
2013 sebesar 38,02\%. Hal ini menunjukkan bahwa pendapatan laba

Berikut adalah tebel hasil analisis data yang digunakan untuk menganlisis penggunaan modal kerja dalam meningkatkan laba pada Industri Sejahtera Mandiri:

Tabel 4

Hasil Analisis Data Yang Digunakan Untuk Menganalisis Penggunaan Modal Kerja Dalam Meningkatkan Laba Pada Industri Sejahtera Mandiri Periode 2011-2013.

\begin{tabular}{|c|l|c|c|c|}
\hline \hline \multirow{2}{*}{ No } & \multicolumn{1}{|c|}{ Rincian } & \multicolumn{3}{|c||}{ Periode } \\
\cline { 3 - 5 } & \multicolumn{1}{|c|}{2011} & 2012 & 2013 \\
\hline 1. & Gross Profit Margin & $35,46 \%$ & $36,45 \%$ & $38,94 \%$ \\
\hline 2. & Operating Profit Margin & $34,21 \%$ & $35,58 \%$ & $38,02 \%$ \\
\hline 3. & Net Profit Margin & $23,87 \%$ & $31,72 \%$ & $35,98 \%$ \\
\hline
\end{tabular}

Sumber: Data Primer

Berdasarkan tabel 4 di atas maka dapat diketahui hasil analisis data yang digunakan untuk mengukur penggunaan modal kerja dalam meningkatkan laba pada Industri Sejahtera Mandiri yaitu:

1. Gross Profit Margin (laba kotor) pada tahun 2012-2013 adalah sebagai berikut: Pada tahun 2011 sebesar $35,46 \%$, tahun 2012 sebesar 36,45\% dan tahun 2013 sebesar 38,94\%. Hal ini menunjukkan bahwa pendapatan laba kotor pada Industri Sejahtera Mandiri dari tahun 2011-2013 mengalami peningkatan.

2. Operating Profit Margin (Laba Sebelum Bunga Dan Pajak) pada tahun 2011-2013 adalah sebagai berikut:

Pada tahun 2011 sebesar 34,21\%, tahun 2012 sebesar $35,58 \%$ dan pada tahun sebelum bunga dan pajak pada Industri Sejahtera Mandiri dari tahun 2011-2013 mengalami peningkatan.

3. Net Profit Margin (Laba Bersih) ) pada tahun 2011-2012 adalah sebagai berikut: Pada tahun 2011 sebesar 23,87\%, tahun 2012 sebesar $31,72 \%$ dan pada tahun 2013 sebesar 35,98\%. Hal ini menunjukkan bahwa pendapatan laba bersih pada Industri Sejahtera Mandiri dari tahun 2011-2013 mengalami peningkatan.

\section{SIMPULAN}

Berdasarkan hasil anilisis penggunaan modal kerja dalam meningkatkan laba pada Industri Sejahtera Mandiri maka penulis mengambil kesimpulan sebagai berikut: 
Berdasarkan ketiga (3) analisis data yang digunakan tersebut (Gross Profit Margin, Operating Profit Margin dan Net Profit Margin) menunjukkan bahwa penggunaan modal kerja dalam meningkatkan laba pada Industri Sejahtera Mandiri pada setiap tahunnya mengalami peningkatan. Indikasi tersebut memberikan petunjuk bahwa penggunaan modal kerja dapat meningkatkan laba, dengan demikian hipotesis yang diajukan penulis dapat diterima.

\section{SARAN}

Berdasarkan kesimpulan yang telah diuraikan di atas, maka melalui penelitian ini penulis memberikan saran-saran sebagai berikut:

1. Sebaiknya Industri Sejahtera Mandiri tetap mempertahankan usahanya karena mampu memberikan laba yang cukup besar.

2. Sebaiknya Industri Sejahtera Mandiri selalu melakukan perhitungan terhadap penggunaan modal kerjan yang digunakan agar dapat mengetahui tingkat kemampuan usahanya dan untuk menghindari pemborosan dalam penggunaan modal kerja.

\section{DAFTAR PUSTAKA}

Munawir. 2004. Analisis Laporan Keuangan. Edisi Keempat. Yogyarta: Liberty.

Simamora, Henry. 2002. Akuntansi Manajemen. Jakarta: UPP AMP YKPN. Soemarso. 2004. Akuntansi Suatu
Pengantar. Jakarta: Edisi Kelima Buku I. Salemba Empat.

Sutrisno. 2001. Manajemen Keungangan, Teori, Konsep an Aplikasi. Edisi Pertama Cetakan Kedua. 